\title{
The Predictors of Obesity Hypoventilation Syndrome in Obstructive Sleep Apnea
}

\author{
Aylin P1htıl11, Züleyha Bingöl2, Esen Kıyan2 \\ ${ }^{1}$ Department of Pulmonary Medicine, İstanbul Haydarpaşa Numune Training and Research Hospital, İstanbul, Turkey \\ 2İstanbul University School of Medicine, Department of Pulmonary Medicine, İstanbul, Turkey
}

Background: As obesity increases, the frequency of obstructive sleep apnea and obesity hypoventilation syndrome increases also. However, obesity hypoventilation syndrome frequency is not known, as capnography and arterial blood gas analysis are not routinely performed in sleep laboratories.

Aims: To investigate the frequency and predictors of obesity hypoventilation syndrome in obese subjects.

Study Design: Retrospective clinical study

Methods: Obese subjects who had arterial blood gas analysis admitted to the sleep laboratory and polysomnography were retrospectively analyzed. Subjects with restrictive (except obesity) and obstructive pulmonary pathologies were excluded. Demographics, Epworth-Sleepiness-Scale scores, polysomnographic data, arterial blood gas analysis, and spirometric measurements were recorded.

Results: Of the 419 subjects, $45.1 \%$ had obesity hypoventilation syndrome. Apnea hypopnea index $(p<0.001)$, oxygen desaturation index $(p<0.001)$ and sleep time with $\mathrm{SpO}_{2}<90 \%(\mathrm{p}<0.001)$ were statistically higher in subjects with obesity hypoventilation syndrome compared to subjects with eucapnic obstructive sleep apnea. The nocturnal mean $\mathrm{SpO}_{2}(\mathrm{p}<0.001)$ and lowest $\mathrm{SpO}_{2}(\mathrm{p}<0.001)$ were also statistically lower in subjects with obesity hypoventilation syndrome. Logistic regression analysis showed that the lowest $\mathrm{SpO}_{2}$, oxygen desaturation index, apnea hypopnea index and sleep time with $\mathrm{SpO}_{2}<90 \%$ were related factors for obesity hypoventilation syndrome.

Conclusion: Obesity hypoventilation syndrome should be considered when oxygen desaturation index, apnea hypopnea index and sleep time with $\mathrm{SpO}_{2}<90 \%$ are high.

Keywords: Apnea hypopnea index, hypercapnia, obesity, obesity hypoventilation syndrome, obstructive sleep apnea
Obesity hypoventilation syndrome (OHS) is a diagnosis of exclusion and should be distinguished from other conditions that are commonly associated with hypercapnia (1). American Academy of Sleep Medicine (AASM) defines OHS as otherwise unexplained daytime hypercapnia [partial carbon dioxide $\left(\mathrm{PaCO}_{2}\right)>45 \mathrm{mmHg}$ ] in obese subjects with body mass index $(\mathrm{BMI})>30 \mathrm{~kg} / \mathrm{m}^{2}$ and is associated with obstructive sleep apnea
(OSA) in $90 \%$ of subjects (2). The frequency of OHS and OSA increase as BMI increases (3-6). While OSA is seen in 50-77\% of subjects with $\mathrm{BMI} \geq 30 \mathrm{~kg} / \mathrm{m}^{2}$, the frequency of $\mathrm{OHS}$ is between $10 \%$ and $38 \%$ in obese OSA subjects $(1,7-14)$.

Subjects with OHS have worse prognosis, poor quality of life and higher health costs compared with subjects with eucapnic OSA (15-16). The incidence of significant co-morbidities such

Address for Correspondence: Dr. Esen Kıyan, Department of Pulmonary Medicine, İstanbul Haydarpaşa Numune Training and Research Hospital, İstanbul, Turkey Phone: +902124142000 e-mail: kiyanesen@gmail.com

Received: 27 December 2015 Accepted: 11 February 2016 •DOI: 10.4274/balkanmedj.2015.1797

Available at www.balkanmedicaljournal.org

Cite this article as:

Pihtılı A, Bingöl Z, Kıyan E. The frequency and predictors of obesity hypoventilation syndrome in obese subjects with obstructive sleep apnea. Balkan Med J 2017;34:41-6

${ }^{\circ}$ Copyright 2017 by Trakya University Faculty of Medicine / The Balkan Medical Journal published by Galenos Publishing House. 
as congestive heart failure, atherosclerotic heart disease, cor pulmonale and pulmonary hypertension in OHS is also higher compared with eucapnic obese and non-obese subjects with OSA $(7,17,18)$. Since arterial blood gas (ABG) analysis and nocturnal capnography are not routinely performed in sleep laboratories, the incidence of OHS is underestimated. While the prevalence of OHS in the adult population is $0.15-0.3 \%$, in OSA subjects it is estimated to be $10-20 \%(7,8,10-13,17)$. Therefore determining the risk factors for OHS is important. The primary aim of this study was to investigate the frequency and predictors of OHS in obese subjects $\left(\mathrm{BMI}>30 \mathrm{~kg} / \mathrm{m}^{2}\right)$ with OSA.

\section{MATERIALS AND METHODS}

In our sleep laboratory, polysomnography is performed by Alice 5 or Compumedics E devices; recordings are performed according to the AASM guideline (19). The AASM 2007 criteria were used for sleep staging and respiratory event scoring (20). We retrospectively screened all medical records of OSA subjects with BMI $>30 \mathrm{~kg} / \mathrm{m}^{2}$ between 1 January 2011 and 10 March 2014. Subjects without OSA, subjects with obstructive [forced expiratory volume 1 second $\left(\mathrm{FEV}_{1}\right)$ / forced vital capacity $(\mathrm{FVC})<70 \%$ ] and restrictive lung diseases (except obesity), use of medication effecting sleep architecture (antihistamines, antidepressant, hypnotic agents etc.), and subjects without ABG analysis were excluded from the study. The demographics, BMI (calculated as weight height-2 ratio), spirometric measurements (ZAN 74N device), daytime ABG at room air (Radiometer ABL 5), Epworth Sleepiness Scale (ESS) scores and polysomnographic data were noted. An ESS score of $\geq 10$ was considered to be excessive daytime sleepiness (21). OHS is defined as a combination of obesity (BMI $>30 \mathrm{~kg} / \mathrm{m}^{2}$ ), chronic daytime hypercapnia $\left(\mathrm{PaCO}_{2}>45 \mathrm{mmHg}\right)$, and sleepdisordered breathing in the absence of other known causes of hypercapnia (2).

Declaration of Helsinki was followed throughout the study. The study was approved by the Ethical Committee of İstanbul University Faculty (Ethic no: 2014/1714).

\section{Statistical analysis}

Statistical analysis was done using the SPSS 21.0 pocket program (AIMS; İstanbul, Turkey). Continuous variables were expressed as mean and standard deviation while categorical variables were expressed as number and percentage. The concordance of normal distribution of all variables was calculated with the Shapiro-Wilk test. If the data were not normally distributed, we used nonparametric tests for dependent variables. Comparisons between groups were carried out with Mann-Whitney U test or Student's t-test. Categorical variables were compared with the chisquare test. Correlation coefficients were calculated using Spearman correlation analysis. Logistic regression analysis was used to determine the related factors of OHS. The area under the receiver operator characteristic (ROC) curve for polysomnographic parameters was analyzed to determine a cut-off level for identifying OHS. To assess the predictive performance of polysomnographic parameters, multiple $2 \times 2$ contingency tables were used to calculate sensitivity and specificity. Statistical significance was considered as $\mathrm{p}<0.05$.

\section{RESULTS}

We screened 500 medical records retrospectively and 81 subjects were excluded because of the exclusion criteria. The study included 419 subjects with OSA (58\% females, mean age: $51.8 \pm 10.9 /$ years, $51.6 \%$ with severe OSA, $25.5 \%$ with moderate OSA and $22.9 \%$ with mild OSA). Of the 419 OSA subjects, $45.1 \%$ had OHS $(n=189 ; 53.9 \%$ females, mean age: $52.9 \pm 10.5 /$ years; $63 \%$ with severe OSA, $18.5 \%$ with moderate OSA, $18.5 \%$ with mild OSA). Table 1 shows the demographics and Table 2 shows the polysomnographic data of all subjects, eucapnic OSA subjects $(n=230)$ and OHS subjects $(n=189)$. Mean age and gender distribution were similar in groups of OHS and eucapnic OSA. Comorbidities were observed in $75.7 \%(n=317)$ of all subjects. These were hypertension (69.7\%), hyperlipidemia (51\%), diabetes mellitus (46.4\%), ischemic heart disease $(21.4 \%)$ and cerebrovascular disease $(2.7 \%)$. For the 131 subjects who have all data for metabolic syndrome (MS), MS frequency was $72.5 \%(n=95)$.

When we compared the data of age and gender matched subjects with eucapnic OSA and OHS, OHS subjects had higher BMI, worse spirometric measurements and worse ABG (Table 1). Comorbidities and MS frequency were similar in both groups. The frequency of subjects with daytime $\mathrm{SpO}_{2}<95 \%$ was significantly higher in the OHS group (48.9\% vs 10.4\%, p<0.001). In the OHS group, AHI, oxygen desaturation index (ODI) and sleep time with $\mathrm{SpO}_{2}<90 \%$ were significantly higher and the nocturnal mean $\mathrm{SpO}_{2}$ and lowest $\mathrm{SpO}_{2}$ were significantly lower than eucapnic OSA subjects. Also, AHI $\geq 30 /$ hour, ODI $\geq 10 /$ hour and subjects with sleep time with $\mathrm{SpO}_{2}<90 \% \geq 20 \%$ were significantly more frequent in the OHS group $(\mathrm{p}<0.001, \mathrm{p}<0.001$, $\mathrm{p}<0.001$ respectively). A comparison of polysomnographic data of OHS and eucapnic OSA groups is shown in Table 2.

BMI was $\geq 40 \mathrm{~kg} / \mathrm{m}^{2}$ in $69.4 \%$ (291/419) of all subjects, most of whom were female (63.6\%). For the subjects with BMI $\geq 40$ $\mathrm{kg} / \mathrm{m}^{2}$, OSA severity was $53.6 \%$ severe, $22 \%$ moderate and $24.4 \%$ mild. OHS frequency was $49.5 \%(n=144)$, ODI was $\geq 10 /$ hour in $99.2 \%(n=133 / 134)$ and sleep time with $\mathrm{SpO}_{2}$ $<90 \%$ was $\geq 20 \%$ in half of OHS subjects with BMI $\geq 40 \mathrm{~kg} / \mathrm{m}^{2}$ 
$(n=72)$. Table 3 shows the demographics, ABG analysis results, polysomnographic and spirometric meausrements of OHS and eucapnic OSA subjects with BMI $\geq 40 \mathrm{~kg} / \mathrm{m}^{2}$.
Spearman correlation showed that $\mathrm{PaCO}_{2}$ was correlated with increased age, BMI, ESS, bicarbonate $\left(\mathrm{HCO}_{3}\right)$, AHI, ODI and sleep time with $\mathrm{SpO}_{2}<90 \%(\mathrm{r}=0.099, \mathrm{p}=0.043 ; \mathrm{r}=0.283$,

TABLE 1. Demographics of all obese OSA subjects, OHS group and eucapnic OSA group

\begin{tabular}{|c|c|c|c|c|}
\hline & All subjects $(\mathrm{n}=419)$ & OHS $(n=189)$ & Eucapnic OSA $(\mathrm{n}=230)$ & $\mathrm{p}$ \\
\hline Age (years) & $51.8 \pm 10.9$ & $52.9 \pm 10.5$ & $50.9 \pm 11.2$ & 0.075 \\
\hline Gender (Female/Male) & $243 / 176$ & $102 / 87$ & $141 / 89$ & 0.137 \\
\hline ESS score & $8.2 \pm 6.1$ & $8.8 \pm 5.9$ & $7.8 \pm 6.3$ & 0.062 \\
\hline ESS score $\geq 10(\%)$ & 41.3 & 45 & 38.3 & 0.163 \\
\hline Co-morbidities (\%) & 75.7 & 78.8 & 73 & 0.172 \\
\hline $\mathrm{FEV}_{1}(\%)$ & $93.8 \pm 9$ & $90.7 \pm 18.8$ & $96.3 \pm 18.8$ & 0.006 \\
\hline $\mathrm{FVC}(\%)$ & $95.5 \pm 18.4$ & $92.4 \pm 18.8$ & $97.9 \pm 17.7$ & 0.005 \\
\hline $\mathrm{FEV}_{1} / \mathrm{FVC}$ & $81.6 \pm 6.4$ & $81.1 \pm 6.6$ & $81.9 \pm 6.2$ & 0.250 \\
\hline Daytime $\mathrm{PaO}_{2}(\mathrm{mmHg})$ & $76.7 \pm 10.7$ & $71.6 \pm 10.6$ & $80.8 \pm 8.9$ & $<0.001$ \\
\hline Daytime $\mathrm{PaCO}_{2}(\mathrm{mmHg})$ & $44.5 \pm 6.3$ & $49.9 \pm 5.0$ & $40 \pm 2.9$ & $<0.001$ \\
\hline
\end{tabular}

BMI: body mass index; $\mathrm{FEV}_{1}$ : forced expiratory volume 1 second; $\mathrm{FVC}$ : forced vital capacity; $\mathrm{PaO}_{2}$ : partial oxygen saturation; ESS: epworth sleepiness scale; MS: metabolic syndrome; $\mathrm{PaCO}_{2}$ : partial carbon dioxide; $\mathrm{SaO}_{2}$ : oxygen saturation; $\mathrm{HCO}_{3}$ : bicarbonate

*Statistical comparison was performed for OHS and eucapnic OSA groups

TABLE 2. Polysomnographic parameters of all obese OSA subjects, OHS and eucapnic OSA groups

\begin{tabular}{|c|c|c|c|c|}
\hline & All subjects $(n=419)$ & OHS $(n=189)$ & Eucapnic OSA $(n=230)$ & $\mathrm{p}$ \\
\hline Total sleep time (minutes) & $422.2 \pm 75.5$ & $423.2 \pm 81.5$ & $421.4 \pm 70.2$ & 0.818 \\
\hline Sleep efficiency $(\%)$ & $84.6 \pm 43.4$ & $83.8 \pm 11.6$ & $81.9 \pm 12.3$ & 0.731 \\
\hline $\mathrm{S} 1+\mathrm{S} 2(\%)$ & $74.1 \pm 38.6$ & $73.6 \pm 15.4$ & $74.5 \pm 50.1$ & 0.830 \\
\hline $\mathrm{S} 3(\%)$ & $18.5 \pm 13.1$ & $17.9 \pm 13.5$ & $19.1 \pm 12.7$ & 0.415 \\
\hline REM (\%) & $9.3 \pm 6.7$ & $8.6 \pm 6.2$ & $9.9 \pm 6.9$ & 0.050 \\
\hline AHI/hour & $39.2 \pm 27.5$ & $46.1 \pm 28.3$ & $33.6 \pm 25.5$ & $<0.001$ \\
\hline REM AHI/hour & $40.9 \pm 26.8$ & $46.2 \pm 26.7$ & $36.9 \pm 25.4$ & 0.001 \\
\hline NREM AHI/hour & $37.9 \pm 28.2$ & $45.1 \pm 29.2$ & $32.4 \pm 26.3$ & $<0.001$ \\
\hline AI/hour & $23.9 \pm 26.8$ & $30.9 \pm 29.8$ & $18.2 \pm 22.6$ & $<0.001$ \\
\hline HI/hour & $14.7 \pm 20.1$ & $14.3 \pm 13.2$ & $14.9 \pm 24.5$ & 0.752 \\
\hline ODI/hour & $46.2 \pm 31$ & $58.5 \pm 32.1$ & $36.3 \pm 26.5$ & $<0.001$ \\
\hline ODI $\geq 10 /$ hour $(\%)$ & 92 & 98 & 87 & $<0.0010$ \\
\hline REM ODI/hour & $49.1 \pm 41.3$ & $57.1 \pm 27.8$ & $42.9 \pm 48.5$ & 0.002 \\
\hline NREM ODI/hour & $46.5 \pm 40.5$ & $57.6 \pm 33.4$ & $37.6 \pm 43.6$ & $<0.001$ \\
\hline Arousal Index/hour & $22.7 \pm 16.7$ & $24.2 \pm 18.3$ & $21.6 \pm 15.3$ & 0.359 \\
\hline Mean $\mathrm{SpO}_{2}(\%)$ & $91.6 \pm 5.5$ & $89.7 \pm 6.4$ & $93.1 \pm 4.1$ & $<0.001$ \\
\hline Lowest $\mathrm{SpO}_{2}(\%)$ & $71.5 \pm 15.2$ & $65.2 \pm 16.5$ & $76.5 \pm 12.1$ & $<0.001$ \\
\hline Sleep time with $\mathrm{SpO}_{2}<90 \%(\%)$ & $21 \pm 26.9$ & $32.4 \pm 30.8$ & $11.7 \pm 18.6$ & $<0.001$ \\
\hline Sleep time with $\mathrm{SpO}_{2}<90 \% \geq 20 \%(\%)$ & 33 & 48 & 20 & $<0.001$ \\
\hline Sleep time with $\mathrm{SpO}_{2}<90 \% \geq 30 \%(\%)$ & 27 & 42 & 15 & $<0.001$ \\
\hline Subjects with AHI $\geq 30 /$ hour (\%) & 51.6 & 63 & 43 & $<0.001$ \\
\hline
\end{tabular}


TABLE 3. General, clinical and polysomnographic properties of subjects with BMI $\geq 40 \mathrm{~kg} / \mathrm{m}^{2}$

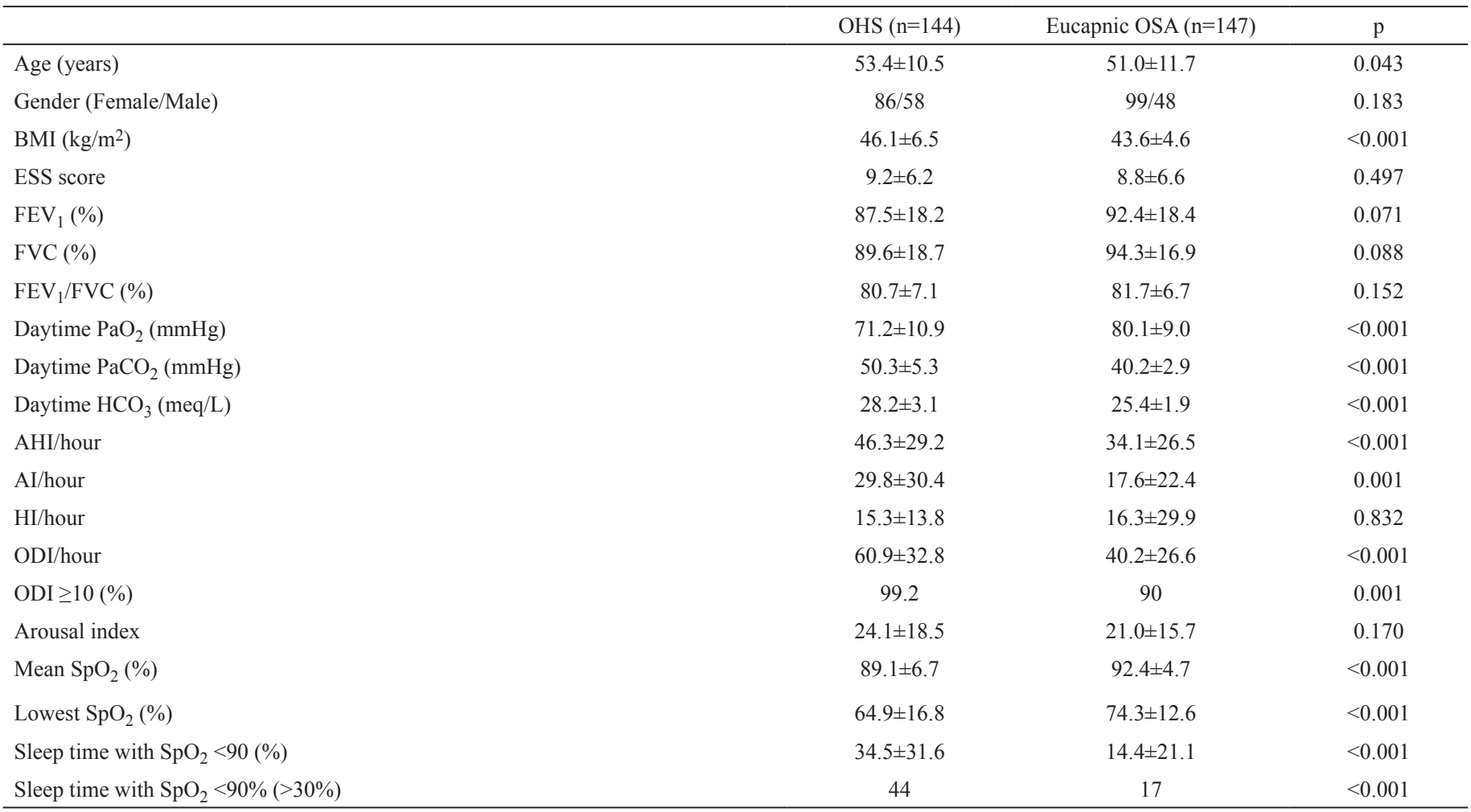

BMI: Body mass index; OSA: obstructive sleep apnea; OHS: obesity hypoventilation syndrome; ESS: epworth sleepiness scale; $\mathrm{FEV}_{1}$ : forced expiratory volume 1 second; FVC: forced vital capacity; $\mathrm{PaO}_{2}$ : partial oxygen saturation; $\mathrm{PaCO}_{2}$ : partial carbon dioxide; $\mathrm{HCO}_{3}$ : bicarbonate; $\mathrm{AHI}$ : apnea hypopnea index; $\mathrm{AI}$ : apnea index; $\mathrm{HI}$ : hypopnea index; ODI: oxygen desaturation index; $\mathrm{SpO}_{2}$ : oxygen saturation calculated by pulse oxymeter

$\mathrm{p}<0.001 ; \quad \mathrm{r}=0.158, \quad \mathrm{p}=0.001 ; \quad \mathrm{r}=0.640, \quad \mathrm{p}<0.001 ; \quad \mathrm{r}=0.269$, $\mathrm{p}<0.001 ; \mathrm{r}=0.414, \mathrm{p}<0.001 ; \mathrm{r}=0.488, \mathrm{p}<0.001$ respectively). On the other hand, $\mathrm{PaCO}_{2}$ was correlated with decreased $\mathrm{FEV}_{1} \%$, $\mathrm{FVC} \%$, daytime partial oxygen saturation $\left(\mathrm{PaO}_{2}\right)$ and nocturnal mean $\mathrm{SpO}_{2}$, as well as having the lowest $\mathrm{SpO}_{2}$ levels $(\mathrm{r}=-0.244$, $\mathrm{p}<0.001 ; \mathrm{r}=-0.223, \mathrm{p}<0.001 ; \mathrm{r}=-0.471, \mathrm{p}<0.001 ; \mathrm{r}=-0.431$, $\mathrm{p}<0.001 ; \mathrm{r}=-0.459, \mathrm{p}<0.001$ respectively).

Parameters correlating with $\mathrm{PaCO}_{2}$ were used for logistic regression analysis. $\mathrm{PaO}_{2}(\mathrm{OR}=1.072, \mathrm{p}<0.001), \mathrm{HCO}_{3}$ $(\mathrm{OR}=0.568, \quad \mathrm{p}<0.001), \quad \mathrm{ODI} \quad(\mathrm{OR}=0.977, \mathrm{p}=0.034) \quad$ and nocturnal lowest $\mathrm{SpO}_{2}(\mathrm{OR}=1.043, \mathrm{p}=0.005)$ were found to be related factors. When logistic regression analysis was performed with only polysomnographic parameters, lowest $\mathrm{SpO}_{2}$, ODI, AHI, and sleep time with $\mathrm{SpO}_{2}<90 \%$ were found to be related to OHS diagnosis $(\mathrm{OR}=1.001, \mathrm{p}=0.042$; $\mathrm{OR}=0.971, \mathrm{p}=0.001 ; \mathrm{OR}=1.023, \mathrm{p}=0.007$; and $\mathrm{OR}=0.969$, $\mathrm{p}=0.026$ respectively). According to the ROC curves, cut-offs were determined for these OHS-related parameters. ROC was 0.632 for ODI. ODI $\geq 36 /$ hour had a sensitivity of $70 \%$ and specificity of $62 \%$. ROC was 0.706 for AHI. AHI $\geq 25 /$ hour had sensitivity of $70 \%$, specificity of $60 \%$. ROC was 0.703 for sleep time with $\mathrm{SpO}_{2}<90 \%$. Sleep time with $\mathrm{SpO}_{2}<90 \%$ $\geq 10 \%$ had a sensitivity of $65 \%$ and a specificity of $70 \%$. In the ROC analysis, we could not find a cut-off for the lowest $\mathrm{SpO}_{2}$ which gives a satisfactory discrimination for OHS diagnosis. The sensitivity and specificity of oxygen saturation $\left(\mathrm{SaO}_{2}\right)<95 \%$, for identifying OHS was $49.24 \%$ and $90.11 \%$, respectively.

\section{DISCUSSION}

Our study is the largest study to investigate the OHS frequency and predictors in obese OSA subjects. Additionally we first demonstrated a diagnostic performance of the nocturnal oxygenation parameters such as ODI, sleep time spent with $\mathrm{SpO}_{2}<90 \%$, and lowest $\mathrm{SpO}_{2}$ by giving a cut-off. In our study, $45.1 \%$ of obese OSA subjects had OHS. This frequency was higher when compared to similar studies in the literature $(14,22)$. The highest frequency in the literature is $38 \%$ but obstructive lung disease was not an exclusion criteria in that study (22). In a study which included 150 subjects with BMI $>35 \mathrm{~kg} / \mathrm{m}^{2}$, the frequency of OHS was also lower (31\%) than our result (3). Higher frequency of OHS in our study can be explained by $70.9 \%$ of the subjects having BMI $\geq 40 \mathrm{~kg} / \mathrm{m}^{2}$. Co-morbidities such as hypertension, type 2 diabetes mellitus, cardiac failure, severe pulmonary hypertension, and risk of 
death are more common in OHS subjects when compared to obese subjects without OSA or obese OSA subjects $(3,7,23$ 27). In our study, the rate of co-morbidities was high in both eucapnic OSA and OHS groups. However, we did not find any significant difference. In our study, we recorded comorbidities according to patient statements and the use of medication. Since we did not analyze laboratory parameters for diagnosing comorbidities, our rates may be underestimated.

In the previous studies comparing OHS subjects with eucapnic OSA subjects, higher BMI and worse spirometric measurements, ABG parameters and nocturnal oxygenation were reported in subjects with OHS $(8,11,12,14,27,28)$. In a recent study performed by Basoglu and Tasbakan (27), a comparison of 59 OHS subjects and 295 obese OSA subjects showed that OHS subjects had a higher rate of daytime sleepiness, decreased FVC, $\mathrm{FEV}_{1}$ and $\mathrm{PaO}_{2}$ and increased $\mathrm{PaCO}_{2}$ and $\mathrm{HCO}_{3}$ levels. Mean and lowest $\mathrm{SpO}_{2}$ during sleep were decreased, and sleep time with $\mathrm{SpO}_{2}<90 \%$ was increased in OHS (27). The same study found sensitivity and specificity of daytime $\mathrm{SaO}_{2}<95 \%$ for OHS diagnosis to be $64.4 \%$ and $73.9 \%$ respectively. Our study similarly showed decreased spirometric measurements, $\mathrm{PaO}_{2}, \mathrm{SaO}_{2}$ and increased $\mathrm{PaCO}_{2}, \mathrm{HCO}_{3}$ in OHS subjects when compared to eucapnic OSA subjects. There was a significant increase in the number of subjects with daytime saturation $<95 \%$ in our OHS group when compared to the eucapnic OSA group (48.9\% vs 10.4\%, p<0.001). Sensitivity and specificity of $\mathrm{SaO}_{2}<95 \%$ for the diagnosis of OHS was $49.24 \%$ and $90.11 \%$, respectively. Similar to the findings of Basoglu and Tasbakan (27), we also demonstrated that daytime $\mathrm{HCO}_{3}$ in $\mathrm{ABG}$ analysis can be a predictor for OHS. Recently, Macavei et al. (28) reported similar findings in a study of 525 subjects of which only $65.5 \%$ were obese and only 216 had $\mathrm{BMI} \geq 35 \mathrm{~kg} / \mathrm{m}^{2}$.

Lowest $\mathrm{SpO}_{2}$, ODI, AHI and sleep time with $\mathrm{SpO}_{2}<90 \%$ were related factors for OHS diagnosis in our study. As a result, we believe that nocturnal hypoxemia is the most important polysomnographic finding for OHS. Our study is the first to demonstrate ODI as a related factor for OHS. We also found that AHI was significantly higher in OHS when compared to eucapnic OSA subjects and we reported AHI as a related factor for OHS. This finding was similar to the findings of Mokhlesi et al. (8) and in contrast to the findings of Resta et al. (12) and Basoglu and Tasbakan (27).

OHS diagnosis is more common in men in the literature but the reason for this dominance is not as clear as it is in OSA (1). In our study group, there was a female dominance and OHS was more frequent in women. This is unusual for subjects with OSA. There are only three previous studies which found similar dominance of females in OHS $(3,25,29)$.
Although retrospective study design is a limitation, our study has the largest population when compared to previous studies. Largest sample size and homogenous study population make our findings important and we believe that our study will contribute to the literature. Additionally giving a cut-off for OHS related parameters is another good point of our study. On the other hand, we did not include any non-OSA OHS subjects, which may be criticized.

In conclusion, OHS is frequently seen in obese subjects with OSA diagnosis. OHS should be considered and ABG should be analyzed in obese subjects with ODI $\geq 36 /$ hour, AHI $\geq 25 /$ hour and sleep time with $\mathrm{SpO}_{2}<90 \% \geq 10 \%$.

Conflict of Interest: No conflict of interest was declared by the authors.

\section{REFERENCES}

1. Mokhlesi B, Tulaimat A. Recent advances in obesity hypoventilation syndrome. Chest 2007;132:1322-36.

2. International Classification of Sleep Disorders, American Academy of Sleep Medicine, Darien, IL 2014.

3. Nowbar S, Burkart KM, Gonzales R, Fedorowicz A, Gozansky WS, Gaudio JC, et al. Obesity-associated hypoventilation in hospitalized patients: prevalence, effects, and outcome. Am J Med 2004;116:1-7.

4. Akinnusi ME, Saliba R, Porhomayon J, EL-Solh AA. Sleep disorders in morbid obesity. Eur J Intern Med 2012;23:219-26.

5. Ryan S, Crinion SJ, McNicholas WT. Obesity and sleep disordered breathing when to 'bad guys' meet. QJM 2014;107:949-54.

6. Olson AL, Zwillich C. The obesity hypoventilation syndrome. Am J Med 2005;118:948-56.

7. Kessler R, Chaouat A, Schinkewitch P, Faller M, Casel S, Krieger J, et al. The obesity-hypoventilation syndrome revisited: a prospective study of 34 consecutive cases. Chest 2001;120:369-76.

8. Mokhlesi B, Tulaimat A, Faibussowitsch I, Wang Y, Evans AT. Obesity hypoventilation syndrome: prevalence and predictors in patients with obstructive sleep apnea. Sleep Breath 2007;11:117-24.

9. Vgontzas AN, Tan TL, Bixler EO, Martin LF, Shubert D, Kales A. Sleep apnea and sleep disruption in obese patients. Arch Intern Med 1994;154:1705-11.

10. Verin E, Tardif C, Pasquis P. Prevalence of daytime hypercapnia or hypoxia in patients with OSAS and normal lung function. Respir Med 2001;95:6936.

11. Laaban JP, Chailleux E. Daytime hypercapnia in adult patients with obstructive sleep apnea syndrome in France, before initiating nocturnal nasal continuous positive airway pressure therapy. Chest 2005;127:7105 .

12. Resta O, Foschino Barbaro MP, Bonfitto P, Talamo S, Mastrosimone V, Stefano A, et al. Hypercapnia in obstructive sleep apnoea syndrome. Neth J Med 2000;56:215-22.

13. Golpe R, Jimenez A, Carpizo R. Diurnal hypercapnia in patients with obstructive sleep apnea syndrome. Chest 2002;122:1100-1.

14. Akashiba T, Kawahara S, Kosaka N, Ito D, Saito O, Majima T, et al. Determinants of chronic hypercapnia in Japanese men with obstructive sleep apnea syndrome. Chest 2002;121:415-21.

15. Hida W. Quality of life in obesity hypoventilation syndrome. Sleep Breath $2003 ; 7: 1-2$. 
16. Berg G, Delaive K, Manfreda J, Walld R, Kryger MH. The use of healthcare resources in obesity-hypoventilation syndrome. Chest 2001;120:37783.

17. Akashiba T, Akahoshi T, Kawahara S, Uematsu A, Katsura K, Sakurai S, et al. Clinical characteristics of obesity-hypoventilation syndrome in Japan: a multi-center study. Intern Med 2006;45:1121-5.

18. Kessler R, Chaouat A, Weitzenblum E, Oswald M, Ehrhart M, Apprill M, et al. Pulmonary hypertension in the obstructive sleep apnea syndrome: prevalence, causes and therapeutic consequences. Eur Respir J 1996;9:78794.

19. Polysomnography Taske Force, American Sleep Disorders Association Standards of Practice Committee. Practice parameters for the indications for polysomnography and related procedures. Sleep 1997;20:406-22.

20. Iber C, Ancoli-Israel S, Stuart Quan M. The American Academy of Sleep Medicine manual for the scoring of sleep and associated events: rules, terminology, and technical specifications. Westchester, IL, 2007.

21. Izci B, Ardic S, Firat H, Sahin A, Altinors M, Karacan I. Reliability and validity studies of the Turkish version of the Epworth Sleepiness Scale. Sleep Breath 2008;12:161-8.

22. Leech JA, Onal E, Baer P, Lopata M. Determinants of hypercapnia in occlusive sleep apnea syndrome. Chest 1987;92:807-13.
23. Atwood CW Jr, McCrory D, Garcia JG, Abman SH, Aheam GS. American College of Chest Physicians. Pulmonary artery hypertension and sleepdisordered breathing: ACCP evidence-based clinical practice guidelines. Chest 2004;126:72-7.

24. Sugerman HJ, Baron PL, Fairman RP, Evans CR, Vetrovec GW. Hemodynamic dysfunction in obesity hypoventilation syndrome and the effects of treatment with surgically induced weight loss. Ann Surg 1988;207:604-13.

25. Mokhlesi B, Tulaimat A, Evans AT, Wang Y, Itani AA, Hassaballa HA, et al. Impact of adherence with positive airway pressure therapy on hypercapnia in obstructive sleep apnea. J Clin Sleep Med 2006;2:57-62.

26. Kauppert CA, Dvorak I, Kollert F, Heinemann F, Jörres RA, Pfeifer M, et al. Pulmonary hypertension in obesity hypoventilation syndrome. Respir Med 2013;107:2061-70.

27. Basoglu OK, Tasbakan MS. Comparison of Clinical Characteristics in Patients with Obesity Hypoventilation Syndrome and Obese Obstructive Sleep Apnea Syndrome: A Case-Control Study. Clin Respir J 2014;8:167-74.

28. Macavei VM, Spurling KJ, Loft J, Makker HK. Diagnostic predictors of obesity-hypoventilation syndrome in patients suspected of having sleep disordered breathing. J Clin Sleep Med 2013;9:879-84.

29. Masa JF, Celli BR, Riesco JA, Hernandz M, Sanchez De Cos J, Disdier C. The obesity hypoventilation syndrome can be treated with noninvasive mechanical ventilation. Chest 2001;119:1102-7. 